\title{
Comparison of dexmedetomidine versus propofol-based anaesthesia for controlled hypotension in functional endoscopic sinus surgery
}

\author{
DK Bharathwaj (iD, SS Kamath* (iD

\begin{abstract}
Department of Anaesthesiology, Kasturba Medical College, Mangalore, Manipal Academy of Higher Education, Manipal, Karnataka, India *Corresponding author, email: shailakamath@ymail.com
\end{abstract}

Background: Increased intraoperative bleeding during functional endoscopic sinus surgery (FESS) affects operative field visibility, which increases both duration of surgery and frequency of complications. Controlled hypotension is an anaesthetic technique in which there is deliberate reduction of systemic blood pressure during anaesthesia. The aim of the study was to compare the efficacy of dexmedetomidine against propofol infusion when used for controlled hypotension during FESS. Methods: A randomised, prospective, and single-blinded study was carried out, which included 80 patients of either sex of ASA grade I \& II who underwent elective FESS. Patients were randomly assigned to two groups: Group A (dexmedetomidine), Group B (propofol). Intraoperative mean arterial pressure (MAP), heart rate (HR), surgical grade of bleeding (based on the Fromme- Boezzart scale), and amount of bleeding were recorded.

Results: Groups were well matched for their demographic data. There was a statistically significant difference $(p<0.05)$ between Group A and Group B in heart rate, mean arterial pressure (MAP) and mean total blood loss, with Group A being effectively in controlled on all three parameters during FESS. However, there was no significant difference $(p>0.05)$ in terms of surgical grade of bleeding between Group A and Group B.

Conclusions: Both dexmedetomidine and propofol infusion are efficacious to facilitate controlled hypotension and haemodynamic stability intraoperatively.

Keywords: controlled hypotension, dexmedetomidine, FESS, propofol, surgical field

\section{Introduction}

Increasing frequency of allergic chronic rhinosinusitis results in a significant health problem and financial burden on society.' Long neglected previously, sinusitis is now recognised as important cause of morbidity. ${ }^{2}$ Diagnosis is primarily clinical, supplemented by radiographic or endoscopic findings. Chronic rhinosinusitis is treated initially by maximum medical therapy, which includes steroids and antibiotics. Surgical intervention is recommended for those patients who are refractory to medical management. ${ }^{3}$ Functional endoscopic sinus surgery (FESS) is widely considered the surgery of choice but success of the surgery depends on intraoperative surgical field conditions. ${ }^{4}$ The objective of FESS is to restore drainage and aeration of paranasal sinuses while preserving normal anatomical structures and mucociliary clearance mechanisms. ${ }^{5}$ Enhancements in equipment, with improved illumination and visualisation has led to better surgical dissection and outcome. ${ }^{6}$

Certain special conditions like Samter's triad ${ }^{4}$ (aspirin sensitivity, nasal polyposis, asthma) and increased tissuevascularisation affect operative field visibility, which increases intraoperative bleeding and duration of surgery. ${ }^{7}$ There are various studies establishing increased chances of major perioperative haemorrhage requiring transfusion during FESS, ${ }^{8}$ which can hinder the implementation of surgery on a day-care basis because of unanticipated hospital stay and readmission rates. ${ }^{9}$ The frequency of other established complications of FESS such as nasal (synechiae, anosmia), intracranial (CSF leak causing meningitis), orbital (optic nerve damage, nasolacrimal duct damage, extraocular muscle damage) are also increased by extensive intraoperative bleeding ${ }^{10}$. Methods to reduce intraoperative bleeding include
Trendelenburg position, preoperative steroid administration, injected and topical local anaesthetics and vasoconstrictors like phenylephrine, maintenance of normothermia, and controlled hypotension by various anaesthetic techniques. ${ }^{11}$

Controlled hypotension is an anaesthetic technique in which there is deliberate reduction of systemic blood pressure during anaesthesia. Hypotensive anaesthesia should be in accordance with the patient's baseline blood pressure rather than a specific target pressure. Mean arterial blood pressure (MAP) can be reduced $30 \%$ below a patient's baseline MAP, with a minimum MAP of $60-70 \mathrm{mmHg}$ in ASA class 1 patients being clinically acceptable. ${ }^{1,2}$

Appropriate patient evaluation and selection, proper positioning and monitoring are recommended before employing controlled hypotension. ${ }^{12}$ The exact mechanism responsible for reducing blood loss is not known, but it may be due to reduction of cardiac output or blood pressure or a combination of both. ${ }^{13}$ There are various pharmacological agents that produce deliberate hypotension such as vasodilators (sodium nitroprusside, nicardipine, nitroglycerin), ${ }^{14}$ adrenergic beta blockers (propranolol, esmolol, labetalol, metoprolol),,$^{14}$ magnesium sulphate, ${ }^{15}$ inhalational agents (isoflurane, ${ }^{16}$ sevoflurane, desflurane ${ }^{13}$ ), intravenous a-2 agonists like dexmedetomidine, ${ }^{17}$ clonidine, ${ }^{18}$ and short-acting opioids like fentanyl or remifentanil. ${ }^{19}$ Total intravenous anaesthesia (TIVA) with propofol is also gaining popularity to facilitate controlled hypotension. ${ }^{13}$

Our study compared the efficacy of dexmedetomidine and propofol infusion when used for controlled hypotension during FESS. 


\section{Materials and methods}

After approval by the institutional scientific and ethics committees, 80 consenting patients fulfilling the inclusion criteria were considered for our study. A pre-anaesthetic checkup was done for all patients, which included a detailed history, general physical and systemic examination. Basic investigations were done (complete blood count, random blood sugar, urea, creatinine) and patients were randomly divided into two groups using block randomisations: Group A (dexmedetomidine) and Group B (propofol), with 40 in each group. After transporting the patients to the operating room, standard monitors like pulse oximetry, non-invasive blood pressure measurement and electrocardiogram were connected, and baseline vitals monitored. Two intravenous lines were secured, one for infusion of dexmedetomidine or propofol and the other for administration of fluids and other drugs respectively. All patients in both groups were started with Ringer's lactate in one IV line; after preoxygenation with $100 \%$ oxygen, patients were premedicated with fentanyl $(1 \mu \mathrm{g} / \mathrm{kg})$ and induced with $2 \mathrm{mg} / \mathrm{kg}$ of propofol in titrated doses followed by rocuronium $0.8 \mathrm{mg} / \mathrm{kg}$ to facilitate endotracheal intubation. The oropharynx was packed with a salinesoaked throat pack. Anaesthesia was maintained with $\mathrm{O}_{2} /$ $\mathrm{N}_{2} \mathrm{O}(50: 50)$ and sevoflurane (MAC .7).

- Group A (dexmedetomidine): All patients received a loading dose of $0.5 \mu \mathrm{g} / \mathrm{kg}$ dexmedetomidine infused over 20 minutes after induction of anaesthesia with a syringe pump followed by continuous infusion of $0.3 \mu \mathrm{g} / \mathrm{kg} / \mathrm{h}$.

- Group B (propofol): After induction, anaesthesia was maintained with nitrous oxide and oxygen. Propofol infusion was started at $12 \mathrm{mg} / \mathrm{kg} / \mathrm{hour}$ for 10 minutes following intubation, then $10 \mathrm{mg} / \mathrm{kg} / \mathrm{hr}$ for the next 10 minutes and continued at $8 \mathrm{mg} / \mathrm{kg} / \mathrm{hr}$.

- In both groups, any episode of MAP ( $<60 \mathrm{mmHg}$ ) was treated with a mephentermine $6 \mathrm{mg}$ IV bolus. The target MAP was determined to be $60-70 \mathrm{mmHg}$.

The surgeon estimated the quality of the surgical field using a predefined category scale adopted from that of the FrommeBoezzart scale. $^{20}$

An average category scale for assessment of the intraoperative surgical field was used:

0 . No bleeding;

1. Slight bleeding-no suctioning of blood required;

2. Slight bleeding-occasional suctioning required. Surgical field not threatened;

3. Slight bleeding-frequent suctioning required. Bleeding threatens surgical field a few seconds after suction is removed;

4. Moderate bleeding - frequent suctioning required. Bleeding threatens surgical field directly after suction is removed;

5. Severe bleeding - constant suctioning required. Bleeding appears faster than can be removed by suction. Surgical field severely threatened and surgery not possible.

The total blood loss was measured from the suction apparatus volume and gauze counting.

Haemodynamic parameters such as $\mathrm{HR}, \mathrm{NIBP}$ and $\mathrm{SpO}_{2}$ were also measured.
Table 1: Age distribution in each group

\begin{tabular}{lcccc}
\hline Group & $\boldsymbol{n}$ & Mean age (years) & SD (years) & $\boldsymbol{p}$-value \\
\hline A & 40 & 35.05 & 10.907 & 0.757 \\
B & 40 & 35.90 & 13.410 & \\
\hline
\end{tabular}

SD: standard deviation.

\section{Statistical analysis}

The data were analysed using the following:

- ANOVA test:

- Tukey test;

- Bonferroni t-test;

- Chi-square test;

- SPSS ${ }^{\circledR} 17.0$ (SPSS Inc, Chicago, IL, USA).

The result was considered statistically significant if the $p$-value was $<0.05$.

\section{Results}

The mean age in group $A$ was 35.05 ( \pm 10.907$)$ and in group B was $35.90( \pm 13.410)$, which is statistically not significant $(p>0.05)$ (Table 1).

The number of male and female patients in Group A was 24 and 16 respectively and in Group B this was 26 and 14 respectively, which is statistically not significant $(p>0.05)$ (Table 2$)$.

The mean HR at induction, 5 minutes, 10 minutes, 20 minutes, 30 minutes, 40 minutes, 50 minutes, 60 minutes, 70 minutes, 80 minutes, 90 minutes, 100 minutes, 110 minutes and 120 minutes was significantly lower in Group A compared with Group B $(p<0.05)$, as seen in Figure 1.

Table 2: Gender distribution in each group

\begin{tabular}{llccc}
\hline Group & Gender & No. & Percentage & $p$-value \\
\hline A & Male & 24 & 60.0 & 0.644 \\
& Female & 16 & 40.0 & \\
B & Male & 26 & 65.0 & \\
& Female & 14 & 35.0 & \\
\hline
\end{tabular}

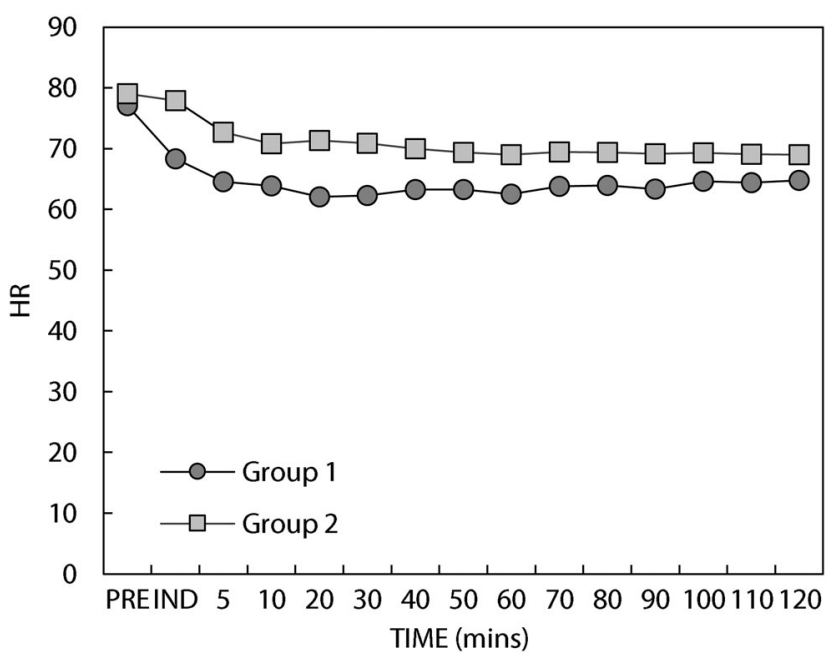

Figure 1: Variation in HR in each group. 


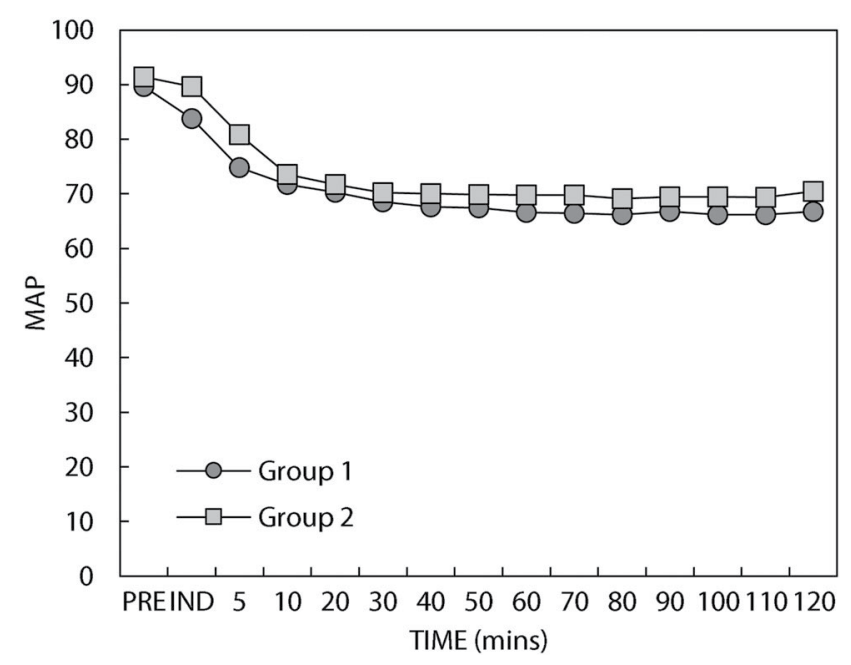

Figure 2: Variation in MAP in each group.

MAP at induction and after 5 minutes was significantly lower in Group A (83.63 \pm 5.978$)$, $(74.80 \pm 8.007)$ when compared with Group B $(89.63 \pm 6.923),(80.83 \pm 5.098)$ with a $p$-value $<0.001$. Intraoperatively also at 60 minutes, 70 minutes, 80 minutes, 100 minutes, 110 minutes and 120 minutes MAP was significantly lower in Group A as compared with Group B as shown in Figure 2.

On the basis of grade of bleeding, all patients were in grade 2 or grade 3 with no statistically significant difference $(p>0.05)$, as seen in Table 3.

The mean total blood loss in Group A $(83.75 \pm 14.796)$ was significantly lower than mean total blood loss in Group B (96.25 $\pm 16.123)(p=0.001, p<0.05)$, as seen in Table 4.

\section{Discussion}

In our study, we chose a target MAP of $60-70 \mathrm{mmHg}$ to provide the best quality of surgical field without any adverse effects. In group $A$, we were able to achieve target MAP within 20 minutes post-induction $(70.25 \pm 7.465)$ and were able to maintain it throughout the surgery. In group $B$, we were able to achieve the desired MAP within 30 minutes post-induction (70.18 \pm 6.381 ) and this was maintained throughout the procedure.

Table 3: Category scale for grades of bleeding

\begin{tabular}{lccc}
\hline Grade & Group A & Group B & Total \\
\hline Grade 0 & 0 & 0 & 0 \\
\hline Grade 1 & 0 & 0 & 0 \\
\hline Grade 2 & $35(87.5 \%)$ & $29(72.5 \%)$ & $64(80 \%)$ \\
Grade 3 & $5(12.5 \%)$ & $11(27.5 \%)$ & $16(20 \%)$ \\
Grade 4 & 0 & 0 & 0 \\
Grade 5 & 0 & 0 & 0 \\
Total & $40(100 \%)$ & $40(100 \%)$ & $80(100 \%)$ \\
\hline
\end{tabular}

Table 4: Mean total blood loss in each group

\begin{tabular}{lcccc}
\hline Group & $\boldsymbol{n}$ & Mean & SD & $\boldsymbol{p}$-value \\
\hline Group A & 40 & 83.75 & 14.796 & 0.001 \\
Group B & 40 & 96.25 & 16.123 & \\
\hline
\end{tabular}

SD: standard deviation.
Mathur et al. ${ }^{21}$ also undertook a similar study comparing dexmedetomidine-isoflurane and propofol-fentanyl based anaesthesia. They used dexmedetomidine at a loading dose of $1 \mu \mathrm{g} / \mathrm{kg}$ over 10 minutes and continuous infusion of a 0.5 $\mu \mathrm{g} / \mathrm{kg} /$ hour dose, which is higher than the dose used for our study. The propofol infusion dose was similar to our study but they started fentanyl infusion in a separate infusion pump at $0.5 \mu \mathrm{g} / \mathrm{kg} /$ hour. Both groups were able to achieve the target MAP within 5 minutes and were able to maintain this intraoperatively. However, they chose a target MAP of 60 to $75 \mathrm{mmHg}$, which is in the higher range when compared with our study.

In our study we observed that intraoperatively both dexmedetomidine and propofol were able to reduce heart rate significantly from baseline with heart rate being lower in group A $(63.93 \pm 3.362)$ when compared with group $B(70.52 \pm 2.589)$ with a significant $p$-value of $<0.05$; however, in our study no episodes of bradycardia $<45 \mathrm{bpm}$ were observed. Bajwa et al.22 also compared the efficacy of infusion of three different drugs, i.e. nitroglycerin, esmolol and dexmedetomidine. The mean heart rate was significantly lower $(p<0.05)$ in the dexmedetomidine group when compared with the other two groups, which is comparable to our study. However, when compared with our study that study used a higher loading dose $(1 \mu \mathrm{g} / \mathrm{kg}$ over 10 minutes) and maintenance dose $(0.5-1 \mu \mathrm{g} / \mathrm{kg} / \mathrm{hour})$.

In our study, mean total blood loss in group A was around $83.75 \pm$ $14.796 \mathrm{ml}$; these results are in accordance with studies conducted by Shah et al. ${ }^{23}(81.67 \pm 27.95 \mathrm{ml})$ : mean total blood loss in group $B$ was significantly higher than for the dexmedetomidine group $(p<0.05)$, which was around $96.25 \pm 16.123 \mathrm{ml}$, which is less than in studies conducted by Ankichetty et al. ${ }^{5}$ with a mean (SD) of $109 \mathrm{ml}( \pm 92.15)$.

In our study based on the quality scale proposed by Fromme and Boezaart, ${ }^{20}$ surgeons graded quality of the surgical field from grade 0 to grade 5 . All the patients were either in grade $2(80 \%)$ or grade $3(20 \%)$ and there was no significant difference between the two groups $(p=0.094, p>0.05)$.

Shams et al. ${ }^{6}$ also employed a scale adopted from Fromme et al. and compared the efficacy of dexmedetomidine (loading dose $1 \mathrm{ug} / \mathrm{kg}$ over 10 minutess followed by maintenance dose of $0.4-0.8 \mu \mathrm{g} / \mathrm{kg} / \mathrm{hour}$ ) and esmolol ( $1 \mathrm{mg} / \mathrm{kg}$ over 1 minute followed by $0.4-0.8 \mathrm{mg} / \mathrm{kg} / \mathrm{hour}$ ) in assessing the quality of the surgical field. Both groups had a median score of 2, i.e. the majority of patients had a score of 2 , which is comparable to our study.

\section{Conclusion}

From the observations in our clinical study, we conclude that both dexmedetomidine and propofol infusion are efficacious and safe drugs for facilitating controlled hypotension. Both drugs can provide haemodynamic stability, an ideal surgical field and reduce blood loss throughout the FESS procedure; however, dexmedetomidine is comparatively better than propofol in controlling heart rate and mean arterial pressure and in reducing blood loss.

\section{ORCID}

SS Kamath (D) https://orcid.org/0000-0002-6824-5122 


\section{References}

1. Fokkens WJ, Lund VJ, Mullol J, et al. European position paper on rhinosinusitis and nasal polyps 2012. Rhinology. 2012;23:1-298.

2. Slavin RG. Sinusitis in adults. J Allergy Clin Immunol. 1988;81:1028-32.

3. Bernic A, Dessouky O, Philpott $C$, et al. Cost effective surgical intervention in chronic rhinosinusitis. Curr Otorhinolaryngol Reports. 2015;3:117-23.

4. Cardesin A, Pontes C, Rosell R, et al. Hypotensive anaesthesia and bleeding during endoscopic sinus surgery. Eur Arch Otorhinolaryngol. 2014;271:1505-11.

5. Ankichetty SP, Ponniah $M$, Cherian $V$, et al. Comparison of total intravenous anaesthesia using propofol and inhalational anaesthesia using Isoflurane for controlled hypotension in functional endoscopic sinus surgery. J Anaesthesiol, Clin Pharmacol. 2011;27(3):328-32.

6. Shams T, El Bahnasawe NS, Abu-Samra M, et al. Induced hypotension for functional endoscopic sinus surgery: A comparative study of dexmedetomidine versus esmolol. Saudi J Anaesthesia. 2013;7(2):175-80.

7. Srivastava $U$, Dupargude $A B$, Kumar $D$, et al. Controlled Hypotension for Functional Endoscopic Sinus Surgery: Comparison of Esmolol and Nitroglycerine. Indian J Otolaryngol Head \& Neck Surgery. 2013;65 (Suppl 2):440-4.

8. Ramakrishnan VR, Kingdom TT, Nayak JV, et al. Nationwide incidence of major complications in endoscopic sinus surgery. IntForum Allergy Rhinol. 2012;2(1):34-9.

9. Singh $G$, McCormack D, Roberts DR. Readmission and overstay after day case nasal surgery. BMC Ear, Nose, Throat Disorders. 2004;4(2.

10. Baker $A R$, Baker $A B$. Anaesthesia for endoscopic sinus surgery. Acta Anaesthesiol Scand. 2010;54(7):795-803.

11. Tan PY, Poopalalingam R. Anaesthetic Concerns for Functional Endoscopic Sinus Surgery. Proceedings of Singapore Healthcare. 2014;23(3):246-53.

12. Rodrigo $C$. Induced hypotension during anesthesia with special reference to orthognathic surgery. Anesth Prog. 1995;42(2):41-58.
13. Tandon U, Sharma A, Kunal K. A Comparative study between use of Propofol and Isoflurane in Endoscopic nasal sinus surgery. Int J Healthcare Biomed Res. 2015;3(3):170-8.

14. Degoute CS, Ray MJ, Manchon $M$, et al. Remifentanil and Controlled hypotension; comparison with nitroprusside or esmolol during tympanoplasty. Can J Anaesth. 2001;48(1):20-7.

15. Elsharnouby NM, Elsharnouby MM. Magnesium sulphate as a technique of Hypotensive anaesthesia. Br J Anaesth. 2006 Jun;96(6):727-31.

16. Mandal P. Isoflurane Anaesthesia for functional endoscopic sinus surgery. Indian J.Anaesth. 2003;47(1):37-40.

17. Rahman NIA, Fouad EA, Ahmed A, et al. Efficacy of different dexmedetomidine regimens in producing controlled hypotension anesthesia during functional endoscopic sinus surgery. Egypt J Anaesthesia. 2014;30(4):339-45.

18. Puthenveettil N, Rajan S, Kumar $L$, et al. A comparison of effects of oral premedication with clonidine and metoprolol on intraoperative hemodynamics and surgical conditions during functional endoscopic sinus surgery. Anesthesia, Essays Res. 2013;7(3):371-5.

19. Lee J, Kim Y, Park $C$, et al. Comparison between Dexmedetomidine and remifentanil for controlled hypotension and recovery in endoscopic sinus surgery. Ann Otol Rhinol Laryngol. 2013;122(7):421-6.

20. Kelly EA, Gollapudy S, Poetkar DM. Quality of surgical field during endoscopic sinus surgery: A systemic literature review of the effect of total intravenous compared to inhalational anaesthesia. Int forum Allergy rhinol. 2013;3(6):474-81.

21. Mathur A, Nambiar PM. Comparison of Dexmedetomidine-Isoflurane versus Fentanyl-Propofol based anaesthesia for controlled hypotension in functional endoscopic sinus surgery. Int J Biomed Res. 2014;5(9).

22. Bajwa SJ, Jalseen K, Ashish K, et al. Nitroglycerine, esmolol and dexmedetomidine for induced hypotension during functional endoscopic sinus surgery: a comparative evaluation. Anaesthesiol Clin Pharmacol. 2016;32:192-7.

23. Shah $\mathrm{H}$, Kulkarni A. A comparative study between Dexmedetomidine infusion and Propofol infusion for maintenance in patients undergoing Functional endoscopic sinus surgery under General anaesthesia. IOSR J Dental Med Sci. 2016;15:82-6. 